\title{
An assessment of efficiency in potential screening for Wilson's disease
}

\author{
TOMOHIRO SAITO
}

From the Department of Environmental Health, Jichi Medical School, Japan*

SUMmARY The efficiency of screening for Wilson's disease by serum caeruloplasmin determination was assessed by analysing the epidemiologic data of 289 affected families in Japan. The estimated gene frequency was $5.5 \times 10^{-3}$. The sensitivity of the screening test was $93 \%$ at a proposed cut-off level of $120 \mathrm{mg} / \mathrm{l}$ and the specificity was $99.83 \%$. In Japan 1500000 children are born every year of whom 50 would be expected to have Wilson's disease. The present analysis of potential screening for all children would grade three of them as false-negatives and identify 2621 as false-positives. An analysis for children only from consanguineous marriages produced a more efficient result, with a much higher predictive value of the positive and case-finding rate. Although the number of patients identified in this latter high-risk screening group was small, it is worth considering as a pilot study.

It is now 70 years since Kinnier Wilson drew attention to the relationship between familial nervous disease and cirrhosis of the liver in the same patients. ${ }^{1}$ The condition was later found to be an autosomal recessive disorder. ${ }^{23}$ Prevention of this genetic disease by administration of penicillamine to asymptomatic patients was claimed to be successful, ${ }^{45}$ and a method of screening by serum caeruloplasmin determination has been considered. A simple and inexpensive way of measuring serum caeruloplasmin using a dried blood spot was recently described. ${ }^{8}$ However, the efficiency of population screening has not previously been fully discussed. ${ }^{5}$

It is the purpose of this paper, therefore, to assess the efficiency of alternative strategies in screening for Wilson's disease in the light of present knowledge based on the analysis of epidemiologic data collected in Japan.

\section{Materials}

All articles published between 1965 and 1977 citing cases of the disease in Japan were traced through Igaku-Chuo-Zasshi (Japana Centra Revuo Medicina) which summarises briefly the contents of Japanese medical journals. A standard questionnaire was then prepared and sent to each hospital involved in the collection of data for the original article. The hospitals were asked for further details of each

-This study was carried out during the author's tenure of a British Council Scholarship as Honorary Research Fellow in the Department of Social Medicine, University of Birmingham. patient and family members. If a questionnaire was not returned, it was filled in by the present author from the original article. Such details were also requested from departments of medicine, paediatrics, and psychiatry in all medical school hospitals in Japan for patients with Wilson's disease who had been seen during the previous 10 or 15 years. The response rate by this latter group was $58 \%$. All data were checked to eliminate any possibility of duplication of registration. A total of $\mathbf{2 8 9}$ families, each with at least one case, was collected.

\section{Methods}

The following particulars were extracted, for each family, to provide data for the analysis:

(1) Consanguinity of parents.

(2) Number of siblings.

(3) Age and health status of each family member, and, if death had occurred, cause and age.

(4) Serum caeruloplasmin concentration (CP) of each person if available.

ESTIMATION OF GENE FREQUENCY AND GENOTYPE FREQUENCY IN THE POPULATION In this genetic analysis 162 families were used for whom information was complete for the first three items listed above.

To estimate the gene frequency in the population, the following formula was used. ${ }^{7}$ It is an extension of 
Dahlberg's formula using $F$ as the coefficient of inbreeding:

$$
q=\frac{c / 16-k F}{(k-c)+(c / 16-k F)}
$$

whereby $q$ is the gene frequency in the population to be estimated, $c$ is the proportion of first-cousin marriages in the population, $F$ is the coefficient of inbreeding in the population, and $\mathrm{k}$ is the proportion of homozygous recessives (the affected individuals) from first-cousin marriages to those from all marriages.

The term $c$ in the Japanese population at the relevant period was taken to be from 0.040 to 0.045 and the corresponding $F$ value from 0.0031 to 0.0035 judging from published data. ${ }^{\circ 9}$ This is based on the observation that in the study the years of parents' marriages were on average seven years earlier than the years of patients' births, most of which were between 1945 and 1965. The term $k=0.3245$ was provided from the present survey.

The gene frequency in the population, $q$, was first estimated, and then the genotype frequency was estimated by the following formulae: ${ }^{10}$

$$
\begin{gathered}
(1-F) q^{2}+F q \text { for homozygous recessives } \\
(1-F) 2 p q \text { for heterozygotes }
\end{gathered}
$$

Table 1 shows the result for the two chosen values of $c$ and $F$. The gene frequency, $q$, was estimated to be between $5.22 \times 10^{-3}$ and $5.96 \times 10^{-3}$. The corresponding frequency of the disease in the population ranged from 1 in 17800 to 1 in 23100 . The rate of consanguineous marriages in Japan has been rapidly decreasing and the proportion of first-cousin marriages, $c$, in the 1980 s will be below $1 \%$. This will lead to a reduction of the disease frequency in the $1980 \mathrm{~s}$, which can be taken as
1 in 30000 for homozygotes and 1 in 91 for heterozygotes.

SERUM CAERULOPLASMIN CONCENTRATION (CP) IN PATIENTS, HETEROZYGDTES, AND NORMAL SUBJECTS

The distribution of $\mathrm{CP}$ in the patients, parents, and healthy siblings of the patients is shown in the Figure. Serum caeruloplasmin concentration reported to the study was measured by various methods and only those expressed in $\mathrm{mg} / \mathrm{l}$ are selected here. The normal range for this quantity was given as over $150 \mathrm{mg} / \mathrm{l}$.

The distribution of CP in the patients did not fit any of the following distributions: normal, log-normal, Poisson, or square root. There was no statistically significant correlation between $\mathrm{CP}$ and age $(\mathrm{p}=0.08)$.

The distribution of $\mathrm{CP}$ in the parents, who are justifiably taken as heterozygotes, fitted well to a normal distribution with a $20 \mathrm{mg} / \mathrm{l}$ interval $\left(\chi_{16}^{2}=10.67,0.80<p<0.90\right)$. Therefore a normal distribution with a mean of $204 \mathrm{mg} / \mathrm{l}$ and a standard deviation of $84 \mathrm{mg} / \mathrm{l}$ was used in the analysis for the CP distribution in heterozygotes. There was no significant correlation between $\mathrm{CP}$ and age in the parents $(0.5<p<0.6)$.

In the Figure, the healthy siblings consist of two distinct groups: normal homozygotes without the gene and heterozygotes (carriers). The theoretical ratio of these two groups is $1: 2$ under autosomal recessive inheritance. There was a statistically significant correlation between $\mathrm{CP}$ and age $(r=-0.36, b=-3.8, a=286,0.01<p<0.02 ;$ $r=$ correlation coefficient, $b=$ slope of regression line, $a=$ intercept of regression line).

We need three distributions of $\mathrm{CP}$ in the analysis-one for patients, one for heterozygotes, and one for homozygotes without the gene. A distribution suitable for the last group was not available in this study; therefore, distributions among

\begin{tabular}{|c|c|c|c|c|c|c|c|}
\hline $\mathbf{k}$ & c & $\mathbf{F}$ & $\mathbf{q}$ & $\begin{array}{l}\text { Homozygote } \\
\text { recessive } \\
(1-\mathrm{F}) \mathrm{q}^{2}+\mathrm{Fq}\end{array}$ & $\begin{array}{l}\text { Homozygote } \\
\text { recessive } \\
1 \text { in }\end{array}$ & $\begin{array}{l}\text { Heterozygote } \\
(1-\mathrm{F}) 2 \mathrm{pq}\end{array}$ & $\begin{array}{l}\text { Heterozygote } \\
1 \text { in }\end{array}$ \\
\hline $\begin{array}{l}0 \cdot 3245 \\
0 \cdot 3245\end{array}$ & $\begin{array}{l}0.040 \\
0.045\end{array}$ & $\begin{array}{l}0.0031 \\
0.0035\end{array}$ & $\begin{array}{l}5.22 \times 10^{-3} \\
5.96 \times 10^{-3}\end{array}$ & $\begin{array}{l}4.33 \times 10^{-5} \\
5.63 \times 10^{-5}\end{array}$ & $\begin{array}{l}23100 \\
17800\end{array}$ & $\begin{array}{l}1.04 \times 10^{-2} \\
1.18 \times 10^{-2}\end{array}$ & $\begin{array}{l}97 \\
85\end{array}$ \\
\hline
\end{tabular}

Table 1 Estimation of the gene frequency and the genotype frequency using

$$
q=\frac{c / 16-k F}{(k-c)+(c / 16-k F)} *
$$

-Where $q=$ the gene frequency in the population

$p=1-q$

$\mathbf{F}=$ coefficient of inbreeding

$c=$ proportion of first-cousin marriages in the population

$k$ = proportion of affected children from first-cousin marriages to those from all marriages 


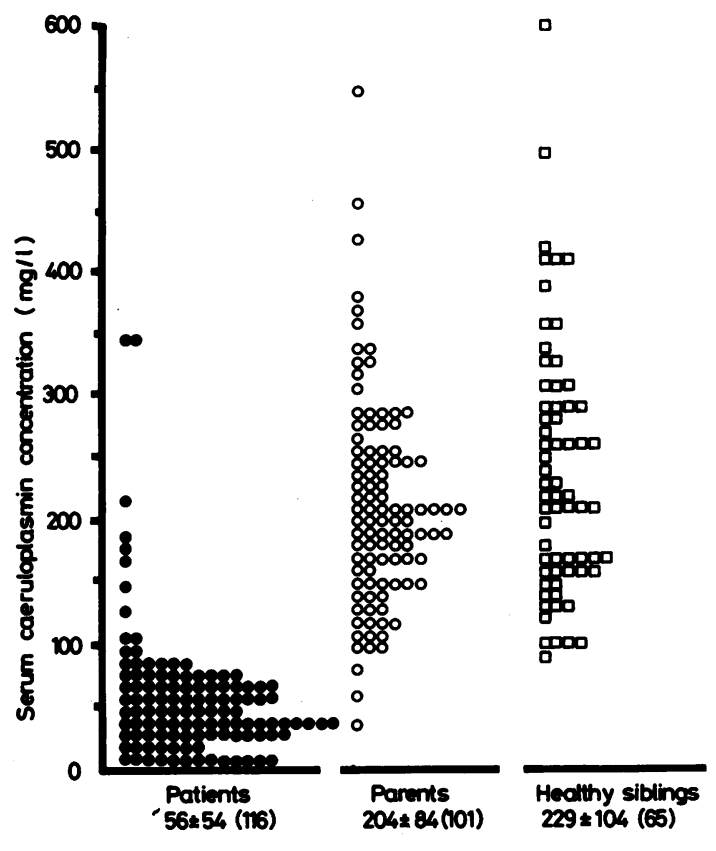

Figure Distribution of serum caeruloplasmin concentrations in patients, parents, and healthy siblings of the patients.

'normal' children were obtained from the literature. ${ }^{11} 12$ Almost all 'normal' children must be homozygotes without this gene. None of the 117 children aged between 2 and 14 in Cox's data ${ }^{12}$ had a value below $150 \mathrm{mg} / \mathrm{l}$. One of the 100 'normal' children in Arima's data ${ }^{11}$ had a value between $110 \mathrm{mg} / \mathrm{l}$ and $160 \mathrm{mg} / \mathrm{l}$. There is a possibility that this child might have been a heterozygote, as the heterozygote frequency was about 1 in 92 in Japan and $26 \%$ of them had values below $150 \mathrm{mg} / \mathrm{l}$ according to the present study. From these data it is justifiable to assume that none of the homozygous children without the gene for Wilson's disease should have a CP below $150 \mathrm{mg} / \mathrm{l}$. This was assumed throughout the following analysis.

\section{ANALYSIS}

The number of babies born in 1978 was 1.71 million and the birth rate has been decreasing. ${ }^{13}$ Therefore the number of candidates for screening every year in the $1980 \mathrm{~s}$ was taken as 1.5 million.

Table 2 shows the sensitivity of the screening test by $\mathrm{CP}$ determination at various cut-off levels, derived from the Figure, and the proportion of heterozygotes whose CP value fell below those levels-namely, the proportion of false-positives among heterozygotes, derived from the assumed normal distribution of $\mathrm{CP}$ in the parents.

Table 3 was constructed from the data already presented. Indices for screening were calculated ${ }^{14}$ when a cut-off level was $120 \mathrm{mg} / \mathrm{l}$. The numbers of patients and heterozygotes were calculated from their estimated frequencies in the population. Forty-seven out of 50 patients are identified in screening because the sensitivity of the test is $8 / 116$. We have three false-negatives. From -Table 2 the proportion of false-positives among heterozygotes is $15.9 \%$, which gives 2621 as the number of false-positives. Because of the assumption that none of the normal homozygotes has a CP value less than $150 \mathrm{mg} / \mathrm{l}$, these 2621 heterozygotes are the only false-positives.

The indices at various cut-off levels calculated in the same way are shown in Table 4 . For the cut-off levels at $170 \mathrm{mg} / \mathrm{l}$ and $200 \mathrm{mg} / 1$, the assumption was made that none of the normal homozygotes had values below those levels.

\section{SCREENING CHILDREN FROM}

CONSANGUINEOUS MARRIAGES

Thirty-nine per cent of the study patients were from consanguineous marriages, and it is of interest to consider screening children from these marriages only. For the sake of simplicity, screening children from first-cousin marriages is considered here.

Thirty-two per cent of the patients, namely $k$ in Table 1, were from first-cousin marriages. However, this proportion decreases as the rate of consanguinity decreases. This relationship is shown in Table 5. The proportion in the 1980 s will be between $5 \%$ and $10 \%$ if the rate of first-cousin marriages is between $0.5 \%$ and $1 \%$. This means that when the rate of first-cousin marriages is $1 \%$, we would identify approximately $10 \%$ of the patients by screening $1 \%$ of children born every year. In figures, we would identify five patients by screening 15000 children at a cut-off level of $120 \mathrm{mg} / \mathrm{l}$. Other indices of screening remain similar

Table 2 Sensitivity of the screening test and the proportion of false-positives among heterozygotes

\begin{tabular}{lllllllll}
\hline Cut-off level (mg/1) & 200 & 170 & 150 & 140 & 130 & 120 & 110 & 100 \\
\hline Sensitivity* & $113 / 116$ & $111 / 116$ & $110 / 116$ & $109 / 116$ & $109 / 116$ & $108 / 116$ & $108 / 116$ & $106 / 116$ \\
Proportion of false-positives among heterozygotes** (\%) $48 \cdot 1$ & $34 \cdot 3$ & $26 \cdot 0$ & $22 \cdot 3$ & $18 \cdot 9$ & $15 \cdot 9$ & $13 \cdot 2$ & $10 \cdot 8$ \\
\hline
\end{tabular}

The proportion of patients whose serum caeruloplasmin level was below these levels in the study

*The proportion of parents whose serum caeruloplasmin level was below these levels. A normal distribution with a mean of $204 \mathrm{mg} / \mathrm{l}$ and a standard deviation of $84 \mathrm{mg} / \mathrm{l}$, derived from the CP distribution of the parents in the Figure, was used as a CP distribution of heterozygotes. 
Table 3 Sensitivity, specificity, and other indices of screening when a cut-off level is $120 \mathrm{mg} / \mathrm{l}$

\begin{tabular}{|c|c|c|c|}
\hline \multirow[b]{2}{*}{ Screening test } & \multicolumn{2}{|c|}{ Wilson's disease } & \multirow[b]{2}{*}{ All tests } \\
\hline & + & - & \\
\hline $\begin{array}{l}+ \\
- \\
\text { All babies }\end{array}$ & $\begin{array}{r}47 \\
3 \\
50\end{array}$ & $\begin{array}{r}2621 \\
1497329 \\
1499950\end{array}$ & $\begin{array}{r}2668 \\
1497332 \\
1500000\end{array}$ \\
\hline $\begin{array}{l}\text { Sensitivity } \\
\text { Specificity } \\
\text { Predictive valu } \\
\text { Efficiency } \\
\text { Children for re }\end{array}$ & sitive & \multicolumn{2}{|c|}{$\begin{aligned} 108 / 116(47 / 50) \times 100=93.1 \% \\
1497329 / 1499950 \times 100=99.8 \% \\
47 / 2668 \times 100=1.8 \% \\
+1497329 / 1500000 \times 100=99.8 \% \\
2668 / 1500000 \times 100=0.18 \%\end{aligned}$} \\
\hline
\end{tabular}

to those in the screening of all children except for the predictive value of the positive, which is about $17 \%$. A case-finding rate (defined here as the ratio of the number of cases identified by screening to the number of children screened) is $0.033 \%(5 / 15000)$ in this type of screening compared with $0.003 \%$ $(47 / 1500000)$ in population screening.

\section{Discussion}

Screening by CP measurement is best carried out on children aged about 2 or 3 . This is supported by the following observations:

(1) None of the 308 cases in this study developed recognisable symptoms or signs before the age of 4 .

(2) The pathological changes in the liver are minimal in asymptomatic patients aged under $4,{ }^{15} 16$ and prevention of the development of the disease is very satisfactory if treatment is started early. ${ }^{45}$

(3) Although the CP in normal subjects is quite low in early infancy, which is therefore not an appropriate time for screening, it has already reached almost its highest level by this age. ${ }^{6}{ }^{12}$ Therefore false-positives are least likely to occur around this age. (Another advantage of this age is that children would be accessible for screening if it were combined with regular immunisation or other preventive measures).

A cut-off level for screening placed at around $120 \mathrm{mg} / \mathrm{l}$ would be most useful, judging from Table 4 . If it is higher, false-positives increase without decreasing false-negatives; if it is lower, the false-negatives increase. It is wise not to place the cut-off level above $150 \mathrm{mg} / \mathrm{l}$ because the chances of normal homozygotes having a CP below this level become high, thus dramatically increasing false-positives.

In the analysis of screening, several assumptions were made, some explicit and others implicit. The following are the most important:

(1) The proportion of first-cousin marriages in the study period was taken to be between $4 \%$ and $4.5 \%$, and in the 1980 s to be between $0.5 \%$ and $1 \%$.

(2) The distribution of the CP of patients aged about 2 would be similar to that of patients from the study data.

(3) The distribution of the CP of heterozygotes aged about 2 would be similar to that of the parents from the study data.

(4) No healthy children of homozygotes without the gene would have CP values less than $150 \mathrm{mg} / \mathrm{l}$.

The relevance to the analysis of these assumptions needs further consideration.

ASSUMPTION 1

The proportion of first-cousin marriages in the population has a substantial influence on the estimation of the gene frequency and hence of the genotype frequency. If the proportion $\mathrm{c}$ is around $3 \%$, which would be the lowest possible value for the whole of Japan at that time, the frequency of the gene becomes about $3.7 \times 10^{-3}$. The highest possible $c$ value would be $6 \%$ and in this case it is around $8.3 \times 10^{-3}$. The estimate of $5.5 \times 10^{-3}$ used in the analysis, however, is very similar to an estimated value from $3.3 \times 10^{-3}$ to $6.6 \times 10^{-3}$ by Arima et al in Japan about 15 years before the present survey. ${ }^{3}$ When $c$ and $F$ change and $F$ is larger than 0.001 the gene frequency $q$ also changes over time. ${ }^{17}$ But the change takes place over more than decades. Therefore the gene frequency used in the analysis through the 1940 s to the 1980 s should also be reasonable.

Another type of question concerning the estimation of the gene and genotype frequency is whether the use of these formulae is justifiable for the whole Japanese population considered as a single

Table 4 Indices for screening at various cut-off levels

\begin{tabular}{|c|c|c|c|c|c|c|c|c|}
\hline Cut-off level (mg/l) & 200 & 170 & 150 & 140 & 130 & 120 & 110 & 100 \\
\hline $\begin{array}{l}\text { Sensitivity } \\
\text { False-negative }(\quad / 50) \\
\text { False-positive }(\quad / 1500000)\end{array}$ & $\begin{array}{l}97 \cdot 4 \\
1 \\
7929\end{array}$ & $\begin{array}{l}95 \cdot 7 \\
2 \\
5654\end{array}$ & $\begin{array}{l}94 \cdot 8 \\
3 \\
4333\end{array}$ & $\begin{array}{l}94 \cdot 0 \\
3 \\
3676\end{array}$ & $\begin{array}{l}94 \cdot 0 \\
3 \\
3115\end{array}$ & $\begin{array}{l}93 \cdot 1 \\
3 \\
2621\end{array}$ & $\begin{array}{l}93 \cdot 1 \\
3 \\
2176\end{array}$ & $\begin{array}{l}91 \cdot 4 \\
4 \\
1780\end{array}$ \\
\hline $\begin{array}{l}\text { Specificity }(\%) \\
\text { Test-positive (referral)* (\%) } \\
\text { Predictive value of positive }(\%) \\
\text { Efficiency }(\%)\end{array}$ & $\begin{array}{r}99 \cdot 47 \\
0 \cdot 53 \\
0 \cdot 61 \\
99 \cdot 47\end{array}$ & $\begin{array}{r}99 \cdot 62 \\
0 \cdot 38 \\
0 \cdot 84 \\
99 \cdot 62\end{array}$ & $\begin{array}{r}99 \cdot 71 \\
0 \cdot 29 \\
1 \cdot 08 \\
99 \cdot 71\end{array}$ & $\begin{array}{r}99 \cdot 75 \\
0 \cdot 25 \\
1 \cdot 26 \\
99 \cdot 75\end{array}$ & $\begin{array}{r}99.79 \\
0.21 \\
1.49 \\
99.79\end{array}$ & $\begin{array}{r}99 \cdot 83 \\
0.18 \\
1 \cdot 76 \\
99.83\end{array}$ & $\begin{array}{r}99.85 \\
0 \cdot 15 \\
2 \cdot 11 \\
99.85\end{array}$ & $\begin{array}{r}99.88 \\
0.12 \\
2.52 \\
99.88\end{array}$ \\
\hline
\end{tabular}

*The proportion of test-positive children among those screened. 
Table 5 Proportion of the affected children from firstcousin marriages to those from all marriages at various levels of $c$ and $F$, estimated by

$$
k=\frac{c(1+15 q)^{*}}{16\{(1-F) q+F\}}
$$

\begin{tabular}{llllll}
\hline $\mathbf{q}$ & $\mathbf{c}$ & $\mathbf{0 . 0 0 5}$ & $\mathbf{0 . 0 1}$ & $\mathbf{0 . 0 4}$ & $\mathbf{0 . 0 5}$ \\
& $\mathbf{F}$ & $\mathbf{0 . 0 0 0 4 4}$ & $\mathbf{0 . 0 0 0 7 8}$ & $\mathbf{0 . 0 0 3 1}$ & $\mathbf{0 . 0 0 3 9}$ \\
\hline $\mathbf{0 . 0 0 5 0}$ & $\mathbf{k}$ & $\mathbf{0 . 0 6 2}$ & $\mathbf{0 . 1 1 6}$ & $\mathbf{0 . 3 3 2}$ & $\mathbf{0 . 3 7 8}$ \\
$\mathbf{0 . 0 0 5 5}$ & $\mathbf{k}$ & $\mathbf{0 . 0 5 7}$ & $\mathbf{0 . 1 0 8}$ & $\mathbf{0 . 3 1 5}$ & $\mathbf{0 . 3 6 1}$ \\
$\mathbf{0 . 0 0 6 0}$ & $\mathbf{k}$ & $\mathbf{0 . 0 5 3}$ & $\mathbf{0 . 1 0 1}$ & $\mathbf{0 . 3 0 0}$ & $\mathbf{0 . 3 4 5}$ \\
\hline
\end{tabular}

"This formula is an algebraic rearrangement of the formula in Table 1 solving for $\mathbf{k}$.

inbreeding unity. It is very likely that in some parts of the country the gene frequency is low and in others it is high, namely, that there exist genetic isolates. In such circumstances the application of the genetic formulae to a whole population leads to a discrepancy between the theoretical and the observed frequency. ${ }^{18}$ The extent of the discrepancy in this analysis is, however, difficult to estimate and the answer would be obtained from the results of screening.

ASSUMPTION 2

It has been shown that asymptomatic patients show very low $C P$ levels even under the age of 4 and some asymptomatic patients were actually found because of their low CP values. ${ }^{5}$ Moreover, no statistically significant correlation was observed between $\mathrm{CP}$ and age among patients. Even if the correlation was statistically significant, possibly with a larger sample size, the slope of the regression line would be around $-1 \cdot 0$ and this would change the age-adjusted distribution of $\mathrm{CP}$ very little. It is not unreasonable, therefore, to assume that the majority of asymptomatic patients would show levels below $100 \mathrm{mg} / \mathrm{l}$. The more relevant question, however, is whether the proportion of asymptomatic patients aged about 2 whose CP values are above the cut-off level is similar to that derived from the Figure. Some authors have indicated that patients with high $\mathbf{C P}$ levels tend to have abnormal liver function, particularly those with severe hepatic failure. ${ }^{19}$ This observation was partly supported in the present study. Sternlieb's data, ${ }^{20}$ however, showed that even some asymptomatic patients had high $\mathrm{CP}$ values, although the proportion was not given. From these observations it could be said that the proportion of patients with CP values above cut-off level would not be high but could well be lower than that used in the analysis. This would decrease the number of false-negatives in screening. For reference, among patients in the present study the proportion with normal CP concentration was similar to the proportions reported in other studies. ${ }^{11} 21$

Another aspect of this question is the variability of $\mathrm{CP}$ within patients over time. Those whose $\mathrm{CP}$ values are high at a time of hepatic failure tend to show lower values after they have recovered from acute failure. ${ }^{19}$ There seem to be some fluctuations of values during the course of the disease, but in most patients the values are fairly constant over time. ${ }^{22} 23$ Therefore variations of CP within individuals would have little effect on the proportion of false-negatives.

\section{ASSUMPTION 3}

The use of the CP distribution in parents as data for heterozygotes aged about 2 requires special attention.

The existence of the correlation between age and $\mathrm{CP}$ value among healthy siblings is largely dependent upon the higher values found in the younger siblings. If these higher values were to consist principally of homozygotes, the correlation with age would disappear. The data on 'normal' subjects indicated 1224 that there was a correlation between $\mathrm{CP}$ and age, and their mean CP value at the age of about 2 was higher than that of adults. The difference ranged from 40 to $100 \mathrm{mg} / \mathrm{l}$. If we assume that there is an inverse relationship between age and CP among heterozygotes and that the difference in the mean $\mathrm{CP}$ level between heterozygous children aged 2 and adults is similar to that among 'normal' subjects, then the proportion of false-positives among heterozygotes ranges from $7 \%$ to $1.4 \%$ at the cut-off level of $120 \mathrm{mg} / \mathrm{l}$ instead of $15.9 \%$ used in the analysis. The corresponding number of false-positives ranges from 1154 to 230 instead of 2621. This was obtained by shifting the normal distribution used as the distribution of $\mathrm{CP}$ among heterozygotes towards a higher value by 40 and $100 \mathrm{mg} / \mathrm{l}$ respectively. Even if there is actually a difference in the mean CP between heterozygous children and heterozygous adults, it would be small. In any event, it would reduce false-positives.

In this connection it should be said that the proportion of heterozygotes with $\mathrm{CP}$ values below the normal range was higher in this study than in previously published papers. ${ }^{11} 18$

\section{ASSUMPTION 4}

It is not impossible that a certain fraction of normal homozygotes have a CP value below $150 \mathrm{mg} / \mathrm{l}$, but the fraction must be very small. If the value of $120 \mathrm{mg} / \mathrm{l}$ is taken as a cut-off level, the proportion of normal homozygotes below this level must be smaller still. The answer could be found only from a large-scale survey, which has not been done on these children. 
The fact that a low CP was observed in patients with other disease ${ }^{19} 25$ may also challenge this assumption. In the present analysis this possibility was not considered. In the screening process, however, only apparently 'healthy' children aged about $\mathbf{2}$ are screened, and the majority of children with these diseases would be easily recognised beforehand. Therefore it is not likely that these diseases would increase the proportion of false-positives among normal homozygotes so greatly as to jeopardise the present analysis.

Menkes's kinky hair syndrome is another disorder with very low $C P$. The frequency of the disease was estimated to be 1 in 35000 in Australia. ${ }^{28}$ The patients were identifiable by CP determination. ${ }^{8}$ It is therefore of interest to consider screening for this disease in combination with screening for Wilson's disease. One of the problems, however, is the age at screening. Most patients with Menkes's syndrome develop the disease in infancy, and pathological changes occur quite early in infancy, ${ }^{26}$ so screening needs to be done at that time, which poses a dilemma. A large overlap of $\mathrm{CP}$ value between affected and normal children is expected in screening for Wilson's disease and possibly for Menkes's disease. It would be premature to discuss the possibility of combined screening without gaining further evidence.

Also, the accuracy and precision of whichever screening test is used need to be assessed.

Apart from the assumptions discussed above, some other questions need to be considered.

The most important question in screening is how to identify the asymptomatic patients among the referrals. There are several ways of distinguishing between genotypes but unfortunately none of them seems to be completely efficient. The clinical test using radio copper seems to be quite effective ${ }^{20}{ }^{27}$ but not complete, and ethical questions remain, even though the dosage of radio copper is claimed to be within acceptable limits. ${ }^{28}$ For patients with some symptoms and signs, making the definitive diagnosis presents some problems. ${ }^{29}$ Making the diagnosis or finding cases among referrals in screening is a difficult one. It was possible to distinguish between three genotypes by the use of radiocopper even among asymptomatic patients. ${ }^{20}$ However, that study did not include the very young. There are not yet enough data on the efficient discrimination of asymptomatic patients in children under 4 to enable this question to be discussed. Again, a reliable answer could be obtained either by the accumulation of appropriate data through the process of making the diagnosis or through screening. The rules for dealing with referrals remain to be formulated.

Screening children from consanguineous marriages seems to give worthwhile results. The predictive value of the positive and the case-finding rate are much higher than in the general population. However, one drawback is that only a proportion of the patients we have every year are identified; the proportion depends upon the rate of consanguinity in the 1980s. Nevertheless, it may be worthwhile to do it as a pilot study. It offers useful information, such as the efficiency of screening and the gene frequencies in different geographical areas, which will be useful for future screening in high-risk areas.

The information on consanguinity will be obtained from the Maternal and child health record book handed to every pregnant woman in Japan, or by asking parents at the time of immunisation or regular health screening of infants.

Recent reports on neonatal screening for congenital metabolic disorders in Japan revealed the following incidence of each disease ${ }^{30}$; phenylketonuria 1/59900; maple syrup urine disease 1/671300; histidinemia 1/8100; homocystinuria 1/145900; galactosemia 1/139800; and congenital hypothyroidism $1 / 8200$. Wilson's disease seems to be comparable to these disorders judging from the principles of screening laid out by Wilson and Junger. ${ }^{31}$ Cost and benefit of the screening need to be assessed further.

In summary, the conclusions of this analysis are as follows. It would be worth screening children from consanguineous marriages for Wilson's disease at the age of about 2 as a pilot study. A cut-off level for screening placed at around $120 \mathrm{mg} / \mathrm{l}$ would be most useful.

I thank Dr. K. Nomiyama, Dr. M. Hayashi, Dr. J. A. H. Waterhouse, and Miss R. A. Allcock for helpful advice, and the attending doctors, too numerous to mention, for their co-operation in providing data for the study. I also thank the British Council for awarding me the scholarship under which this study was carried out.

Reprints from Dr. Tomohiro Saito, Department of Environmental Health, Jichi Medical School, 3311-1 Minamikawachi-machi, Kawachi-gun, Tochigi-ken, Japan 329-04.

\section{References}

${ }^{1}$ Wilson SAK. Progressive lenticular degeneration: A familial nervous disease associated with cirrhosis of the liver. Brain 1912; 34: 295-509.

2 Bearn AG. Genetic and biochemical aspects of Wilson's disease. Am J Med 1953; 15: 442-449. 
${ }^{3}$ Arima M, Kurumada T, Kamoshita S. Genetic studies on Wilson's disease: II Mode of inheritance, geographical distribution and gene frequency. Brain and Nerve 1963; 15: $29-35$.

4Arima M, Komiya K. Prevention of Wilson's disease. Paediatria Universitalis Tokyo 1970; 18: 22-24.

${ }^{5}$ Sternlieb I, Scheinberg IH. Prevention of Wilson's disease in asymptomatic patients. $N$. Engl J Med 1968; 278: 352-359.

-Aoki T, Nakahashi M. New screening method for Wilson's disease. Lancet 1977; ii: 1140 .

${ }^{7} \mathrm{Li}$ CC. In: First course in population genetics: Pacific Grove, California: The Boxwood Press, 1976: 358-63.

${ }^{8}$ Imaizumi Y, Shinozaki N, Aoki H. Inbreeding in Japan: Results of a nationwide study. Japanese Journal of Human Genetics 1975; 20: 91-107.

${ }^{9}$ Shull WJ, Neel JV. Consanguineous marriages in Japan. In: Shull WJ, Neel JV. The effect of inbreeding on Japanese children. New York: Harper and Row, 1965: $11-30$.

${ }^{10} \mathrm{Li}$ CC. In: First course in population genetics: Pacific Grove, California: The Boxwood Press, 1976: 235-8.

${ }^{11}$ Arima M. Early diagnosis and prevention of Wilson's disease. Saishin-Igaku 1969; 24: 1219-25 (in Japanese).

${ }^{12}$ Cox DW. Factors influencing serum ceruloplasmin levels in normal individuals. $J$ Lab Clin Med 1966; 68: 893-904.

${ }^{13}$ Health and Welfare Statistics Association. In: Koseino-Shihyo, Tokyo 1980; 27(9): 48-9 (in Japanese).

14 Whitby LG. Screening for disease: definition and criteria. Lancet 1974; ii: 819-22.

${ }^{15}$ Shikata T. Liver changes in Wilson's disease. Neurol Med 1974, 1: 593-8 (in Japanese).

${ }^{16}$ Sternlieb I, Scheinberg IH. The diagnosis of Wilson's disease in asymptomatic patients. JAMA 1963; 183: 747-50.

${ }^{17}$ Cavalli-Sforza LL, Bodmer WF. In: The genetics of human populations. San Francisco: WH Freeman, 1971: 341-85.
${ }^{18}$ Stern C. In: Principles of human genetics, 3rd edn. San Francisco: WH Freeman, 1973: 487.

${ }^{19}$ Scheinberg IH, Sternlieb I. Wilson's disease and the concentration of ceruloplasmin in serum. Lancet 1963; i: $1420-1$.

${ }^{20}$ Sternlieb I, Scheinberg IH. The role of radiocopper in the diagnosis of Wilson's disease. Gastroenterology 1979; 77: $138-42$.

${ }^{21}$ Sternlieb I. Wilson's disease as a gastroenterologic problem. Am J Gastroenterol 1964; 42: 264-70.

${ }^{22}$ Arima M, Komiya K. Wilson's disease: Clinical course and treatment. J Pediatr Pract 1965; 28: 144-60.

${ }^{23}$ Takemoto T. Clinical and genetic studies on Wilson's disease. Med J Kagoshima Univ 1970; 22: 338-67 (in Japanese with an English abstract).

${ }^{24}$ Hirayama C. Normal value of serum protein fraction. In: Hirayama C, Uda S, ed. Serum protein. Tokyo: Ishiyaku Shuppan, 1979; 251 (in Japanese).

${ }^{25}$ Sternlieb I, Scheinberg IH. Ceruloplasmin in health and disease. Ann NY Acd Sci 1961; 94: 71-6.

${ }^{28}$ Danks DM, Campbell PE, Stevens BJ, Mayne V, Cartwright E. Menkes's kinky hair syndrome: An inherited defect in copper absorption with widespread effects. Pediatrics 1972, 50: 188-201.

${ }^{27}$ Sternlieb I, Morell AG, Bauer CD, Combes B, de Bobes-Sternberg S, Scheinberg IH, Brosseau JC. Detection of the heterozygous carrier of the Wilson's disease gene. J Clin Invest 1961; 40: 707-15.

${ }^{28} \mathrm{Chervu}$ LR, Sternlieb I. Docimetry of copper radionuclides. J Nucl Med 1974; 15: 1011-3.

${ }^{29}$ Sternlieb I. Diagnosis of Wilson's disease. Gastroenterology 1978; 74: 787-93.

${ }^{30}$ Oura T. Present status and new problems in the newborn screening for inborn errors of metabolism. Congenital Anomalies 1981; 21: 9-16 (in Japanese with an English abstract).

${ }^{31}$ Wilson JMG, Junger G. Principles and practice of screening for disease. Geneva: WHO, 1968. 